\title{
Study of Synthesis and Physicochemical Properties of Arginine Derived Cationic Surfactants
}

\author{
Jyoti D. Mhatre ${ }^{1, *}$, Pravin U. Singare ${ }^{2}$ \\ ${ }^{1}$ Department of Chemistry, Shri. Jagdishprasad Jhabarmal Tibrewala University, Jhunjhunu, 333001, Rajasthan \\ ${ }^{2}$ Department of Chemistry, Bhavan's College, Munshi Nagar, Andheri (West), 4000058, Mumbai
}

\begin{abstract}
The invention concerns the preparation of cationic surfactants derived from the condensation of an acid chloride, preferably a fatty acid with a number of carbon atoms 8 and 14 with esterified amino acids, preferably basic-type amino acids, like (L)-Lysine and (L)-arginine, more preferably (L)-arginine. The method comprises a first step in which the esterification of the amino acid with an alcohol is performed and a second step for the condensation with a chloride of fatty acid, using Schotten Baumann conditions. These surfactants constitute a novel class of chemicals of low toxicity with excellent surface properties and considerable antimicrobial activity. The physicochemical properties of the compounds of invention are compared against commercially available LAE (Lauroylarginine Et ester) and SDS (sodium dodecyl sulfate).
\end{abstract}

Keywords Cationic Surfactants, Arginine, Schotten Baumann

\section{Introduction}

Surfactants have been employed with success in a wide variety of fields and, due to their surface properties, have been subjected to intense study in systems involving interaction with membranes. This class of compounds combines at least one hydrophilic head group and one hydrophobic tail in the same molecule, and it is well known that the nature and structure of these groups significantly influence the behaviour of such molecules. Some biological toxicity has been recognized in the traditional surfactants, hence limiting their applications.

Long chain $\mathrm{N}^{\alpha}$-acyl amino acids have been studied by many groups with the aim to obtain mild surfactants for preservative applications[1-2]. Cationic surfactants derived from the condensation of fatty acids and esterified dibasic amino acids, such as from lauric acid and arginine, in particular the Et ester of the lauramide of the arginine monohydrochloride (LAE), may be used for the protection against the growth of the microorganisms. The cationic surfactants of this type are also effective against virus infections. Addition of LAE to cultures of Herpes virus type 1 Vaccinia virus and bovine parainfluenzae 3 virus leads to nearly complete reduction of the virus organisms in these cultures, such effects being observed after 5 and $60 \min [3]$. Sugimoto and Toyoshima[4] have studied N $\alpha$-Cocoyl-L-Arginine ethyl ester, DL-Pyroglutamic acid salt as an inactivator of

* Corresponding author:

jyoti.mhatre27july@gmail.com (Jyoti D. Mhatre)

Published online at http://journal.sapub.org/ajoc

Copyright (C) 2012 Scientific \& Academic Publishing. All Rights Reserved
Hepatitis B surface antigen. Lourdes et al[5], have synthesized a novel family of dicationic arginine-monoglyceride surfactants. Compounds having alkyl chain $\mathrm{C} 10-\mathrm{C} 14$ attached to the glycerol through esters and a dicationic polar head from the Arginine. An Article by M.R.Infante et al[6] has studied the synthesis and properties of $\mathrm{N}^{\alpha}$-Lauroyl-L-Arginine dipeptides as methyl esters (cationic surfactants) and free $\alpha$-carboxylic acids (amphoteric surfactants). They found properties of these compounds are comparable to the cationic monomer derivatives methyl ester of $\mathrm{N}^{\alpha}$-Lauroyl-L-Arginine and of the amphoteric monomer derivative $\mathrm{N}^{\alpha}$-Lauroyl-L-Arginine reported earlier. J.Seguer et al[7] also reported synthesis and physicochemical properties of $\mathrm{N}^{\alpha}$-acyl-L-arginine dipeptides with a chain length between 8-16 carbon atoms. From the studies the author has summarized that the introduction of an appropriate long chain (14 carbon atoms) to the amino function of a mixture of amino acids yields an interesting multifunctional compound to be applied as soft preservative peptide surfactant in cosmetics, food and dermo-pharmaceutical formulations.

Over the past decade, developments on enzyme technology in non-conventional media have opened new possibilities for the synthesis of surfactants from natural sources. We were particularly interested in preparation of $\mathrm{N}^{\alpha}$-acyl arginine esters (C8-C16), which will be used as microbicides in future. In this work, two arginine-derivative surfactants, arginine- $N$-Caproyl ethyl ester (CAE) and arginine- $N$-Myristoyl ethyl ester (MAE), are studied. This study showed that the efficiency of single-chain surfactants is affected by their alkyl chain length, with improving effect upto 14 carbon tail surfactants. 


\section{Chemistry}

We have synthesized at multigram scale two pure homologues with alkyl chain of 8 (CAE) and 14 (MAE) carbon atoms (Fig. 1). We have shown that essential structural factors for their surfactant activity include both the length of the fatty residue and the presence of the protonated guanidine function.

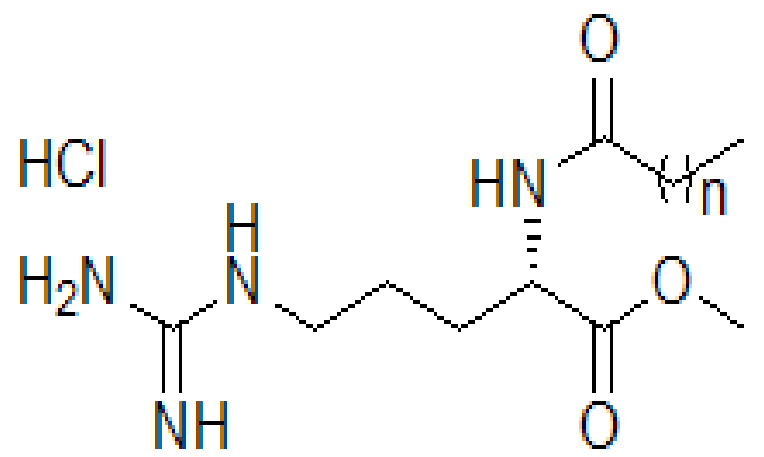

Figure 1. Molecular structure of the $\mathrm{N}^{\alpha}$-acyl arginine ethyl ester surfactants; $n=6$ CAE, $n=12$ MAE, $n=10$ LAE

C. Solans et al[8a,b] synthesized $\mathrm{N}^{\alpha}$-lauroyl arginine methyl ester Hydrochloride (LAM), in gel emulsions of the system water $/ \mathrm{C}_{14} \mathrm{E}_{4} /$ decane and compared with those obtained in conventional dimethylformamide (DMF) media and found that LAM formation is faster in gel emulsions at short times. Pere Clapes et al[9], have published a review wherein enzymatic synthesis, physicochemical and biological properties as well as the potential uses of Amino-acid based surfactants are described. Rondel C. et al[10] have described the acylation of amino acids by acid chlorides with from 8-12 carbon atoms in alkaline aqueous medium following Schotten-Baumann reaction.

The $N$-acylation of the amino terminal arginine was prepared by condensation of fatty acids to arginine methyl ester hydrochloride using Schotten Baumann conditions. The preparation of arginine alkyl esters was carried out in solvent free systems using the same alcohol reagent. The choice of the solvent is crucial to allow the solubilisation of both the hydrophobic and hydrophilic (acyl-donor) components. We report the chemical synthesis and the study of some physical properties such as the critical micellar concentration in the following sections of this paper. The experimental protocol was specifically chosen to be compatible with the small amount of surfactants obtained via synthesis.

\section{Experimental Procedures}

\subsection{General Reagents and Synthetic Method}

L-Arginine was purchased from Ajinomoto Co., Octanoic acid, Myristic acid and Sodium Dodecyl sulfate (SDS) were received from Sigma-Aldrich. LAE. $\mathrm{HCl}\left(\mathrm{N}^{\alpha}\right.$-Lauroyl arginine ethyl ester Hydrochloride) was supplied by local supplier. Solvents used were of analytical grade or higher purity and supplied by Sigma-Aldrich. The homogeneity of compounds was checked by thin-layer chromatography on aluminium plates (Kieselgel G, Merck\}. The solvent systems were (A) chloroform/methanol/acetic acid (8.5:10:5\}; and (B) chloroform/methanol (7:3). Ninhydrin developer solution was used for qualitative analysis of free amino groups, the guanidyl group of arginine and peptide bonds, respectively.

Nuclear Magnetic Resonance $\left({ }^{1} \mathrm{H}\right.$ NMR) and all the NMR measurements were performed with Bruker, Avance 300 spectrometer model at $300 \mathrm{MHz}$ in a $5 \mathrm{~mm}$ direct probe $(\mathrm{BBO}$ BB-1H) using $\mathrm{CDCl}_{3}$ as a solvent. Surface Tension was measured using Stalagmometer.

\section{Preparation of Fatty Acid Chlorides}

In a four necked round bottom flask equipped with stirrer and thermo pocket charge 0.1 mole of Fatty Acid at room temperature and heat to $40^{\circ} \mathrm{C}$., then add 0.15 mole of Thionyl Chloride under Nitrogen atmosphere over a period of 1 hour and heat the reaction mixture to reflux for $1 \frac{1}{2}$ hour to obtain crude Acid Chloride.

\section{Preparation of L-Arginine ethyl ester dihydrochloride}

In a $250 \mathrm{ml}$ round bottom flask charge Ethyl alcohol followed by the addition of L-Arginine free base. Stir vigorously to get a clear solution. Charge via addition funnel conc. $\mathrm{HCl}$ of $37 \%$ strength slowly controlling exotherm. Apply heat and reflux for 4-5 hours. Cool to 60 degree $\mathrm{C}$ and add more conc. $\mathrm{HCl}$ and reflux further till the completion of the reaction with simultaneous removal of ethanol. Apply vacuum and distill residual alcohol. Cool the residual mass to get crude L-Arginine ethyl ester dihydrochloride.

\section{Preparation of $\mathrm{N} \alpha$-Acyl L-Arginine ethyl ester compounds by Schotten Baumann reaction.}

The crude reaction product obtained in the first step is dissolved in water and the $\mathrm{pH}$ of the solution is brought to a specific $\mathrm{pH}$ value $5.5-7$ by the addition of aqueous sodium hydroxide. The $\mathrm{pH}$ of the reaction is carefully kept constant at this value until completion of the reaction. To this solution, add 0.96 equivalent of Octanoyl/Myristoyl chloride drop-wise, whereby the temperature of the mixture is kept at a temperature of $10-15^{\circ} \mathrm{C}$ by means of an appropriate cooling bath containing ethylene glycol. After completion of the reaction, the stirring is maintained for a further two hours, after which the $\mathrm{pH}$ of the solution is adjusted to a final value of 5.5-7 with hydrochloric acid or sodium hydroxide. Finally, the crude reaction product is obtained either by filtration or by distillation.

Compound: N- $\alpha$-Octanoyl-L-Arginine ethyl ester (CAE) - Prepared by reaction between L-Arginine Et ester diHCl and Octanoyl chloride in the presence of aqueous $\mathrm{NaOH}$. Clear Yellowish oil. MW 328, ESI-MS; m/z $329(\mathrm{~m}+) ; 1 \mathrm{H}$ NMR: $\delta \mathrm{H}(\mathrm{CDCl} 3), 0.89[\mathrm{t}, 3 \mathrm{H},(\mathrm{CH} 3$ alkyl chain)], $1.29[\mathrm{~s}$, $11 \mathrm{H},(4 \mathrm{CH} 2$, alkyl chain), (OCH2-CH3)], 1.5-1.7[m, $4 \mathrm{H}$, (CH2-CH2-CO-NH-), (-CH2-CH2-CH2-NH-)], 2.27[t, 2H, (NH-CH(COO)-CH2-CH2-)], 3.1-3.3[(-NH-C(=NH)-NH2)] $3.5-3.7[2 \mathrm{H},(-\mathrm{CH} 2-\mathrm{CO}-\mathrm{NH}-)], 4.2[\mathrm{~m}, 2 \mathrm{H},(-\mathrm{OCH} 2-\mathrm{CH} 3)]$ (-NH-CH-COO-)], 7.2[s, (-NH-C $(=\mathrm{NH})-\mathrm{NH} 2)]$.

Compound: N- $\alpha$-Myristoyl-L-Arginine ethyl ester (MAE) - Prepared by reaction between L-Arginine Et ester diHCl 
and Myristoyl chloride in the presence of aqueous $\mathrm{NaOH}$. White solid. MW 412.61, ESI-MS; m/z $413(\mathrm{~m}+)$; 1H NMR: $\delta \mathrm{H}(\mathrm{CDCl} 3), 0.89[\mathrm{t}, 3 \mathrm{H},(\mathrm{CH} 3$ alkyl chain $)], 1.29[\mathrm{~s}, 23 \mathrm{H}$, (10CH2, alkyl chain), (-OCH2-CH3)], 1.6-1.9[m, 7H, (CH2-CH2-CO-NH-), (-CH2-CH2-CH2-NH-), (-NH-C(=NH)-NH2)], 2.26[t, 2H, (-CH2-CO-NH-)], 3.2[2H, (-CH2-CH2-CH2-NH-)], 4.2[m, $2 \mathrm{H}, \quad(-\mathrm{OCH} 2-\mathrm{CH} 3), \quad 4.43[\mathrm{~m}, \quad 1 \mathrm{H}, \quad(-\mathrm{NH}-\mathrm{CH}-\mathrm{COO}-)$, $7.2[(-\mathrm{NH}-\mathrm{C}(=\mathrm{NH})-\mathrm{NH} 2)]$.

\subsection{Analytical Methods}

The characteristic properties of the compounds synthesized are summarized in Table 1. The completion of reaction was monitored by TLC. Their mass spectra showed only one mass peak corresponding to the molecular ion. Pure compounds were obtained after several crystallisations in methanol/acetonitrile. The chemical structure of these compounds was checked by NMR. The proton NMR spectra were in concordance with the proposed structure.

Table 1. Characteristic Properties of the Synthesized Compounds

\begin{tabular}{|c|c|c|c|c|}
\hline & $\begin{array}{c}\text { Appear- } \\
\text { ance/mp }\end{array}$ & Rf & Mol. Formula & $\begin{array}{c}\mathrm{m} / \mathrm{e}\left[\mathrm{M}^{+} \mathrm{H}\right. \\
]^{+}\end{array}$ \\
\hline $\begin{array}{c}\text { L-Arg. } \\
\text { OEt.di } \\
\mathrm{HCl}\end{array}$ & Sticky mass & $\begin{array}{c}0.4 \\
0\end{array}$ & $\begin{array}{c}\mathrm{C}_{8} \mathrm{H}_{18} \mathrm{~N}_{4} \mathrm{O}_{2} .2 \mathrm{H} \\
\mathrm{Cl}\end{array}$ & --- \\
\hline $\mathrm{CAE}$ & $\begin{array}{c}\text { Clear Yellow } \\
\text { Oil }\end{array}$ & $\begin{array}{c}0.6 \\
8\end{array}$ & $\mathrm{C}_{16} \mathrm{H}_{32} \mathrm{~N}_{4} \mathrm{O}_{3}$ & 329 \\
\hline MAE & $\begin{array}{c}\text { White solid } \\
65-68^{\circ} \mathrm{C}\end{array}$ & $\begin{array}{c}0.4 \\
5\end{array}$ & $\mathrm{C}_{22} \mathrm{H}_{44} \mathrm{~N}_{4} \mathrm{O}_{3}$ & 413 \\
\hline
\end{tabular}

\subsubsection{Method for Surface tension}

A tensiometer (Stalagmometer) with a Wilhelmy plate was used for surface tension measurements $(\gamma)$. Water/surfactant solutions of different concentrations were prepared and allowed to equilibrate at $25^{\circ} \mathrm{C}$ between 4 and $10 \mathrm{hr}$.

\subsubsection{Method for critical micellar concentration (CMC)}

The critical micellar concentration (CMC) was determined from the break point of the surface tension/concentration curves.

\subsection{Results and Discussions}

Single chain Arginine based surfactants have CMC values ca $1-10 \mathrm{mM}$ and these values decrease linearly as the number of methylene groups in the alkyl chain increase[11]. The high $\mathrm{CMC}$ values observed for the $\mathrm{CAE}$ are due to the fact that it has a less hydrophobic chain than that of LAE and MAE. In fact, a longer, more hydrophobic chain results in lower surface tension. The surface Tension and $\mathrm{CMC}$ values of CAE and MAE are compared against commercially available LAE and SDS (Table 2). The study indicates that both the values of surface tension and CMC are comparable and sometimes even lower than that of SDS. They have the ability to decrease the surface tension of water until a constant value is reached They therefore have interesting surface-active properties.

Table 2. Critical micellar concentration of $\mathrm{N}^{\alpha}$-acylarginine ester and references

\begin{tabular}{|c|c|c|}
\hline & $\mathrm{CMC}(\mathrm{mg} / \mathrm{L})$ & $\gamma(\mathrm{mN} / \mathrm{m})$ \\
\hline CAE & $>1500$ & $27.0 \pm 0.5$ \\
\hline LAE & $410 \pm 40$ & $25.5 \pm 0.5$ \\
\hline MAE & $350 \pm 30$ & $24.0 \pm 0.5$ \\
\hline SDS & $290 \pm 30$ & 39.1 \\
\hline
\end{tabular}

In Summary, amino acid-based surfactants constitute a class of bio-based surfactants with excellent surface properties, the antimicrobial studies of which will be published in our next publication.

\section{ACKNOWLEDGEMENTS}

We are indebted to Dr. Vilas Chopdekar and Dr. Richard Stockel for technical support to this project. We are also thankful to V \& V Pharma Industries for providing Laboratory to conduct experiments.

\section{REFERENCES}

[1] M. R. Infante, P. Erra, R. Juliá, M. Prats and J.J. Garcia Dominguez, "Surface active molecules: Preparation and properties of long chain $\mathrm{N}^{\alpha}$-acyl-L- $\alpha, \omega$, guanidine alkyl acid derivatives," Int. J. Cosmet. Sci., vol. 6, pp. 275-282, (1984).

[2] M. R. Infante, J. Molinero, P. Bosch, P. Erra and R. Juliá, "Lipopeptidic surfactants. I. Neutral $\mathrm{N}^{\alpha}$ lauroyl L-arginine dipeptides from pure amino acids," J. Am. Oil Chem. Soc., Vol. 66 (12), pp. 1835-1839, (1989).

[3] R. Bonvila,, "Antiviral use of cationic surfactant," PCT Int. Appl. (2008), WO 2008014824

[4] Y. Sugimoto and S. Toyoshima, "N $\mathrm{N}^{\alpha}$-Cocoyl-L-Arginine Ethyl Ester, DL-Pyroglutamic acid Salt, As an Inactivator of Hepatitis B surface Antigen," Antimicrobial Agent and Chemotherapy, vol.16 (3), pp. 329-332, Sept. 1979

[5] L. Pe'rez, A. Pinazo, M. T. Garc1'a, M. del C. Mora' $n$ and M. R. Infante, " Monoglyceride surfactants from arginine: synthesis and biological properties," New J. Chem., vol. 28, pp. 1326-1334, (2004).

[6] M.R.Infante, J.Molinero and P. Erra, "Lipopeptidic surfactants. I. Acidic and Basic $\mathrm{N}^{\alpha}$ lauroyl L-arginine dipeptides from pure amino acids," J. Am. Oil Chem. Soc., Vol. 69 (7), pp. 647-652, (1992).

[7] J.Seguer, J. Molinero, A. Manresa, J. Caelles and M.R. Infante, "Physicochemical and antimicrobial properties of $\mathrm{N}^{\alpha}$-acyl-L-arginine dipeptides from acid-hydrolyzed collagen, J. Soc. Cosmet. Chem., vol. 45, pp. 53-63, (1994). 
[8] C. Solans, A. Pinazo, G. Calderó and M. R. Infante, "Highly concentrated emulsions as novel reaction media," Colloids and Surfaces A: Physicochemical and Engineering Aspects, vol. 176, pp. 101-108, (2001).

[9] A. Pinazo, M. R. Infante, P. Izquierdop and C. Solans, "Synthesis of arginine based surfactants in highly concentrated water-in-oil emulsions," J. Chem. Soc., Perkin Trans 2, pp. 1535-1539, (2000).

[10] P. Clapés and M. R. Infante, "Amino acid-based surfactants. Enzymatic Synthesis, properties and Potential Applications,"
Biocatalysis and Biotransformation, vol. 20 (4), pp. 215-233, (2002).

[11] C. Rondel, I. Alric, Z. Mouloungui, J. Blanco, F. Silvestre, "Synthesis and Properties of Lipoamino Acid-Fatty Acid Mixtures: Influence of the Amphiphilic Structure," J. Surfact. Deterg., vol. 12, pp. 269-275, (2009).

[12] C. Morán, P. Clapés, F. Comelles, T. Garcia, L. Pérez, P. Vinardell. M. Mitjans and M. R. Infante, "Chemical structure/property relationship in Single chain Arginine-based surfactants," Langmuir, vol. 17, pp. 5071-5075, (2001). 